Etnográfica

Revista do Centro em Rede de Investigação em

Antropologia

vol. $14(2) \mid 2010$

Vol. $14(2)$

\title{
Micol Brazzabeni, La Scuola di Carta: una ricerca di antropologia della formazione tra gli insegnanti tikmu'un del minas gerais
}

\section{Bruna Franchetto}

\section{(2) OpenEdition}

Journals

\section{Edição electrónica}

URL: https://journals.openedition.org/etnografica/344

DOI: 10.4000/etnografica.344

ISSN: 2182-2891

\section{Editora}

Centro em Rede de Investigação em Antropologia

Edição impressa

Data de publição: 1 junho 2010

Paginação: 407-411

ISSN: 0873-6561

\section{Refêrencia eletrónica}

Bruna Franchetto, «Micol Brazzabeni, La Scuola di Carta: una ricerca di antropologia della formazione tra gli insegnanti tikmu'un del minas gerais», Etnográfica [Online], vol. 14 (2) | 2010, posto online no dia 20 julho 2012, consultado o 12 fevereiro 2022. URL: http://journals.openedition.org/etnografica/344 ; DOI: https://doi.org/10.4000/etnografica.344

Este documento foi criado de forma automática no dia 12 fevereiro 2022.

\section{(c) (1) \&}

Etnográfica is licensed under a Creative Commons Attribution-NonCommercial 4.0 International License. 


\title{
Micol Brazzabeni, La Scuola di Carta: una ricerca di antropologia della formazione tra gli insegnanti tikmu'un del minas gerais
}

\author{
Bruna Franchetto
}

\section{REFERÊNCIA}

Micol Brazzabeni, La Scuola di Carta: una ricerca di antropologia della formazione tra gli insegnanti tikmu'un del minas gerais, Roma, Centro d'Informazione e Stampa Universitária, 313 páginas.

1 No dia 25 de fevereiro de 2010, a Assessoria de Comunicação do Ministério Público (MP) do Estado de Minas Gerais (Brasil) divulgou notícia a respeito da inspeção realizada pelo MP em aldeias maxakali. A notícia contém no título a expressão: "situação desoladora". A inspeção tinha como objetivo averiguar a crise sanitária, que está vitimando crianças maxakali, no meio de mais um surto de diarréia, e a atuação dos dois órgãos governamentais responsáveis pelo bem-estar das populações indígenas, Funai (Fundação de Apoio ao Índio, Ministério da Justiça) e Funasa (Fundação Nacional de Saúde).

2 O procurador da República Edílson Vitorelli Diniz Lima afirma que a situação encontrada é pior do que se poderia imaginar:

Os Maxakali destacam-se por ainda ser um povo que mantém suas tradições culturais, sendo inclusive um dos poucos no Brasil que ainda conservam e se comunicam em seu próprio idioma. No entanto, estão completamente abandonados, em condições absolutamente precárias de saúde e moradia.

O relatório ainda constata que não existe, em nenhuma aldeia, qualquer infra-estrutura sanitária, assim que, por exemplo, 
As condições de armazenamento da água também são precárias. Há na aldeia Pradinho duas caixas que são abastecidas com a água de um poço artesiano. Após o surto, a água passou a ser fornecida com caminhão pipa, mas, durante a inspeção, o MPF constatou que a própria água fornecida pela Copasa não continha cloro, ou seja, não estava devidamente tratada. As caixas d'água existentes estão com as tampas quebradas, acarretando possibilidade de proliferação de insetos, com especial risco de dengue.

O lixo invade as aldeias, o alcoolismo se agrava: "há donos de bares que retêm os cartões de bolsa família dos índios, vendendo para os mesmos a crédito, e controlando todos os seus recursos financeiros", diz o prefeito de uma cidade próxima.

Assim sobrevivem, hoje, os tikmn, auto-denominação dos índios mais conhecidos como maxakali, pelas vicissitudes perversas da hetero-denominação de povos indígenas. Assim deve tê-los encontrados Micol Brazzabeni, autora do belo livro (e tese) La Scuola di Carta, por ocasião de sua breve experiência de pesquisa de campo. O fortíssimo impacto desta experiência, com todas as marcas deixadas no corpo visível e invisível da autora, é transmitido ao leitor página após página. Foi um impacto multifacetado, múltiplo: odores, cores, texturas, o fluxo sonoro de uma língua desconhecida, interações dificilmente decodificáveis (ou impossíveis de serem decodificadas), o agudo descompasso entre os discursos oficiais e a realidade local, nas aldeias, dentro e fora da "escola".

Qual escola? É a pergunta obrigatória para um observador inteligentemente ingênuo ou ingenuamente inteligente, como Brazzabeni, que acaba de chegar em terra brasileira, em uma área indígena, entre os tikmn. Foi preciso vir de muito longe, ser um "estrangeiro", estar livre das amarras da retórica dos "especialistas" em "educação indígena", quadros de instituições governamentais e não governamentais, ter sensibilidade antropológica, um bom olhar etnográfico, sofrer (no corpo), para enxergar o que é e não é uma escola indígena e quem são os professores indígenas de uma escola indígena, no Brasil. o livro de Brazzabeni é o resultado de uma pesquisa ainda incipiente, mas que explicita questões iniciais e algumas conclusões absolutamente saudáveis, política e intelectualmente. Ele está hoje, felizmente, em boa companhia, junto com trabalhos (poucos, ainda) com as mesmas qualidades e com a coragem de ver e dizer para além das aparências.

Brazzabeni não teve tempo para ler estes trabalhos, fruto de uma nova linha de pesquisas em antropologia da "educação escolar indígena", no Brasil. É interessante descobrir as muitas afinidades e o mesmo olhar, compartilhados por Célia Collet (2006), em sua tese de doutorado sobre a escola entre os bakairi, povo de língua karib do estado de Mato Grosso, tese intitulada significativamente Ritos de Civilização e Cultura, e por Ingrid Weber, cuja dissertação se tornou um livro publicado: Um Copo de Cultura: Os Huni Kuin (Kaxinawá) do Rio Humaitá e a Escola (Weber 2006).

8 Se o livro de Brazzabeni se intitula La Scuola di Carta (A Escola de Papel), o capítulo conclusivo do livro de Weber é "O papel da escola", uma frase cuja ambigüidade a autora esclarece logo no começo, comentando uma foto. Esta retrata o interior da escola da aldeia kaxinawá de São Vicente, do rio Humaitá (estado do Acre, Brasil), decorada com os cartazes da candidatura do líder e professor Vicente Sabóia nas eleições locais, no ano de 2000, e com fileiras de balõezinhos brancos, feitos com as páginas de cartilhas e cadernos. A história interessantíssima de Vicente Sabóia é contada no livro: um dos principais líderes indígenas, ele foi protagonista da história kaxinawá desde a libertação da dependência quase escrava dos patrões seringalistas, 
das lutas pela demarcação das terras, da aliança com os projetos de resgate econômico e cultural trazidos por organizações governamentais e não governamentais. Vicente Sabóia foi o precursor do uso da escrita, da alfabetização e da escola (uma proto-escola improvisada, itinerante e sempre provisória, que antecedeu aquela erguida pelos cariú, os brancos, no centro da aldeia de, justamente, São Vicente). A escola imaginada de Brazzabeni-tikmn é a escola imaginada de Weber-Kaxinawá, o cupixau-escola. Cupixau era a antiga casa comunal kaxinawá, que, antes de desaparecer nos tempos da escravidão nos seringais, congregava as famílias em rituais e encontros:

Eis, literalmente o papel da escola [...] uma brincadeira, mas uma brincadeira séria, como diriam os Kaxinawá [...] [A] escola, enquanto lugar multifuncional centralizador da vida coletiva vem preenchendo um espaço nos dias atuais, nos quais a tendência à dispersão, me parece, tem sido cada vez mais premente [...]. [Em] grande parte das aldeias indígenas do Acre, a casa da escola é, hoje, a construção em torno da qual uma aldeia se legitima e se define. (Weber 2006: 218)

Weber cita Peter Gow (1990), que tece os mesmos comentários sobre a escola entre os piro:

“[...] a escola pode não 'funcionar' de acordo com o papel que normalmente concebemos para ela, mas isto não significa que ela não funcione, ou que ela seja uma instituição alheia ao contexto." Ao longo do último século, se houve a preocupação com a preservação de algo, foi a de reconstituir, sempre que possível, a vida junto aos parentes e à fartura, não importando de que forma... (Weber 2006: 218-219)

10 A escola é este lugar de viver junto e de fartura (os recursos que ela consegue trazer), é isto que importa, e hoje é o lugar da "cultura", dos projetos trazidos pelos brancos "bem-intencionados" de ONG e instituições governamentais. Hoje, na escola se realiza o "resgate" de tradições no mínimo "adormecidas": os cantos do cipó, festas, a tecelagem, a língua kaxinawá, narrativas míticas. Os índios, diz Weber,

Nunca tiveram qualquer preocupação em preservar a "cultura", nos termos, em que, hoje, vem sendo definida (e levada para eles)... o que passou é passado e o lugar de guardar o passado é a memória. Em meio a este ambiente amazônico, a escola, geralmente a única construção da aldeia que não costuma ser de palha e paxiúba, é agora o espaço por excelência da "preservação" (2006: 221-222). ${ }^{1}$

11 A distância geográfica, histórica e cultural que separa tikmn, kaxinawá e bakairi não impede que nos surpreendamos, a cada passo, com as agudas semelhanças das etnografias da "escola indígena". Tomemos a tese de Collet (2006).

12 A partir de uma análise articulada sobre organização social e cosmologia, modos e métodos de formação de pessoas e história, Collet procura compreender, assim como fazem Weber e Brazzabeni, o lugar destinado e designado à escola na vida social bakairi (povo de língua karib, estado de Mato Grosso). Ela propõe que a escola veio ocupar um espaço que antes do "encontro" com os brancos era ocupado exclusivamente pelas cerimônias coletivas do kado, realizadas para familiarizar "espíritos sub-aquáticos", "donos" dos recursos dos quais os bakairi dependem para a reprodução de suas famílias. Collet destaca três dimensões significativas. A primeira diz respeito à substituição do complexo ritual kado pela escola como principal espaço de cerimônias coletivas, substituição iniciada no tempo em que o Serviço de Proteção ao Índio esteve à frente do Posto Indígena bakairi (dos anos 20 até o início dos anos 60 do século passado). Em segundo lugar, a autora identifica as não poucas analogias entre kado e escola, ambos "espaços" para performances pan-familiares em que "roupas", comidas, desenhos (escrita) e práticas ritualizadas são, todas, formas de "transformar-se" no 
"outro" (no caso do kado, em "espíritos", no caso da escola, em branco/civilizado). A terceira dimensão, finalmente, é a da imitação, que caracteriza a assunção da chamada "cultura indígena" pela escola, fazendo com que um kado simplificado se transforme nos ritos das apresentações ou festas escolares (festas cívicas de "santificação" da nação brasileira como as do Dia do Índio e de Sete de Setembro, além das híbridas "festas de santo").

Há outros paralelos indiscutíveis entre as experiências escolares desses três povos indígenas. Bakairi e tikmn conviveram longamente com os missionários-lingüistas do Summer Institute of Linguistics (SIL), absorvendo sua ideologia e práticas educacionais (escolares), onde se destacam a escrita e a alfabetização em língua indígena, com produção de cartilhas e livrinhos de "literatura indígena", práticas e produtos marcados pelo dúbio e discutível rótulo de "intercultural". ${ }^{2}$

14 A escola é o espaço-tempo de olhar o papel escrito e de escrever no papel. Outro aspecto comum às três etnografias da escola é a "descoberta" de uma concepção xamânica da escrita, hoje objeto de crescente interesse e presente em todas, ou na maioria das sociedades das terras baixas. ${ }^{3}$ A escrita é kene para os Kaxinawá; kene, os desenhos da anaconda mítica nas "mirações" dos "rituais do cipó" (ayawasca), são os caminhos do conhecimento percorridos pelos xamãs que por eles conduzem os iniciandos. Para os bakairi, a escrita é iwenyly, termo usado para a pintura corporal, desenhos dos cestos, bancos, cuias e apás. O iwenyly pintado nos corpos dos participantes do kado, por exemplo, não é uma "representação" dos seres/espíritos peixe, cobra, morcego, libélula, etc. - mas um meio de transformar-se neles. Iwenyly se distingue de ekudyly, a cópia-imitação, como no desenho "representativo". Segundo Collet (2006), o modelo iwenyly serviria também para tratar do modo de "copiar" (no sentido de "transpor" de um lugar a outro) o contexto escolar oficial a fim de transformar-se em civilizado; o modelo ekudyly serviria para falar da representação dos "costumes" bakairi, tratada por "cultura", que acontece principalmente em certas cerimônias escolares.

Se falei muito de outros textos e autores, quase contemporâneos ao trabalho de Brazzabeni e que dele se aproximam para além de qualquer expectativa, é para destacar o quanto este último está afinado com a boa e competente literatura recentíssima sobre o tema da "escola imaginada" para e pelos povos indígenas no Brasil. A escola é algo que chega de fora, às vezes uma dádiva, às vezes um instrumento de destruição, mas quase sempre digerido, deslocado, mascarado para assumir funções que os próprios índios lhe atribuem e gerem, nas barbas dos bem-intencionados e quase sempre decepcionados agentes da assistência do Estado. Mesmo se o livro La Scuola di Carta não é resultado de uma pesquisa de campo de tempos longos e com domínio mínimo da língua indígena, o que teria dado em uma etnografia propriamente dita da "escola", com suas práticas e representações, não posso não destacar, também, os aspectos originais do livro, que acrescentam novos e instigantes insights.

Brazzabeni dedica metade dos oito capítulos do seu livro à mais completa e fundamentada síntese da história, crítica, da escolarização de populações indígenas no Brasil que eu conheça. Somente isto já merece uma imediata tradução e publicação no Brasil, uma vez corrigidas algumas poucas informações equivocadas e uma vez atualizada com a bibliografia pertinente mais recente. Em segundo lugar, é bom dizer que o objeto de análise não é tanto a escola tikmn, tão imaginada quanto inapreensível, mas os atuais percursos de formação dos professores indígenas, um segmento que se 
consolida em todas as sociedades indígenas em que a escola se consolida, novos líderes, assalariados, escribas e escritores, verdadeiros mediadores e tradutores entre mundos em constante conflito, aliança e negociação. É aqui que reside a contribuição original do livro de Brazzabeni, que vem se somar, enriquecendo-as, comparativamente, às análises de Collet e Weber. A autora, enfim, mostra que logrou na superação do principal desafio, o de realmente enxergar as coisas pela perspectiva dos tikmn.

Para concluir, repito o que escrevi na apresentação do livro de Weber. La Scuola di Carta é a metamorfose de uma tese em que a autora analisou com brilho práticas e discursos da "educação (escolar) indígena", em suas versões anteriores e posteriores a assim chamada "educação diferenciada, específica, intercultural e bilíngüe", bandeira da ideologia de Estado e de seus aparelhos, inclusive delegados, de assistência. E antes e depois da "invenção da cultura", objetivação de um modo de ser no mercado simbólico da modernidade. Essas escolas imaginadas são, hoje, um híbrido criativo de transfromações, elas, sim, realmente interculturais, lá onde o discurso oficial não enxerga nem interculturalidade, nem especificidade, nem diferença. Ideólogos e praticantes da política "educacional" para índios encontram neste livro provocações saudáveis e um material generoso para meditar.

\section{BIBLIOGRAFIA}

COLLET, Célia Letícia Gouvêa, 2001, "Quero Progresso Sendo Índio": O Princípio da Interculturalidade na Educação Escolar Indígena, dissertação de mestrado, Rio de Janeiro, Museu Nacional/Universidade Federal do Rio de Janeiro.

-, 2006, Ritos de Civilização e Cultura: A Escola Bakairi, tese de doutorado, Museu Nacional/ Universidade Federal do Rio de Janeiro.

FRANCHETTO, Bruna, 2008, “A guerra dos alfabetos: os povos indígenas entre o oral e o escrito", Mana: Estudos de Antropologia Social, 14 (1): 31-59.

GOW, Peter, 1990, "Could Sangama read? The origin of writing among the Piro of Eastern Peru", History and Anthropology, 5: 87-103.

-, 2001, Of Mixed Blood: Kinship and History in Peruvian Amazonia. Nova Iorque, Oxford University Press.

MACEDO-TINOCO, Sílvia, 2006, Ecolya et Karetajar: maître d'école, maître de l'écriture: l'incorporation de l'écriture et de l'école par les amérindiens wayãpi de l'Amapari (Brésil) et de l'Oyapok (Guyane Française), tese de doutorado, Paris, École de Hauts Études en Sciences Sociales.

MACEDO, Sílvia Lopes da Silva, 2009, "Xamanizando a escrita: aspectos comunicativos da escrita ameríndia”, Mana: Estudos de Antropologia Social, 15 (2): 509-528.

TUGNY, Rosangela Pereira de (org), 2009a, X yõg kutex xi hemex yõg kutex: Cantos e Histórias do Morcego-Espírito e do Hemex. Rio de Janeiro, Beco do Azougue.

- (org), 2009b, Mõgmõka yõg kutex xi ãgtux: Cantos e Histórias do Gavião-Espírito. Rio de Janeiro, Beco do Azougue. 
WEBER, Ingrid, 2006, Um Copo de Cultura: Os Huni Kuin (Kaxinawá) do Rio Humaitá e a Escola. Rio Branco, Editora da Universidade Federal do Acre e Núcleo de Transformações Indígenas (NuTI).

\section{NOTAS}

1. Aos tikmn, que cantam incessantemente para e com os espíritos, em condições de vida quase miserável, sobre uma terra destruída por séculos de desmatamento e exploração selvagem (por parte dos não-indígenas), se destinam, hoje, projetos culturais de grande envergadura, que passam tanto pela escola como fora dela, e que flexionam intenções de preservação e divulgação. Refiro-me aos livros organizados por Tugny (2009a e 2009b) contendo uma exaustiva documentação dos cantos rituais, belíssimas fotos de autoria das mulheres, vídeos de grande qualidade. Uma exposição no Museu do Índio do Rio de Janeiro mostrará em breve tudo isso e os tikmn virão ao Rio para cantar e se mostrar, longe das "guerras" nas e perto de suas aldeias, episódios de violência e medo também testemunhados por Brazzabeni.

2. Veja-se Collet (2001) para uma análise crítica da noção de interculturalidade presente nas políticas de educação escolar indígena no Brasil, noção de matriz missionária e reciclada no discurso oficial (governamental e não) a partir dos anos 90. Brazzabeni também examina a questão em seu livro. Veja-se também Franchetto (2008) para uma abordagem etnolingüística e política da "ortografização" de línguas indígenas, em distintos percursos históricos e culturais (povos indígenas do Alto Xingu e de Roraima).

3. A este propósito, ver também Gow (1990) para os piro, e Macedo-Tinoco (2006) ou Macedo (2009) para uma visão geral e o caso específico dos wayãpi.

\section{AUTORES}

BRUNA FRANCHETTO

UFRJ; CNPq 